\title{
CARACTERIZAÇÃO FUNCIONAL DO SISTEMA REPRODUTIVO DA AROEIRA- VERMELHA (Schinus terebinthifolius Raddi), EM FLORIANÓPOLIS-SC, BRASIL ${ }^{1}$
}

\author{
MAURÍCIO LENZI² \& AFONSO INÁCIO ORTH ${ }^{3}$
}

\begin{abstract}
RESUMO - Determinou-se a dioicia como sistema reprodutivo de S. terebinthifolius (Anacardiaceae), em uma área com influência antrópica e em outra área de restinga, no município de Florianópolis-SC. Durante dois períodos reprodutivos, desenvolveram-se os tratamentos de polinização livre e cruzada manual, realizados em plantas de ambos os sexos, e tratamentos de anemofilia, agamospermia e partenocarpia, realizados apenas em plantas femininas. Os tratamentos de polinização que resultaram em frutificação foram o livre, maior média 45\%, e cruzada manual, maior média 56,2\%, confirmando-se funcionalmente a dioicia da espécie. Os demais tratamentos de polinização não resultaram em frutificação, indicando que o gineceu reduzido das flores masculinas não é funcional, a espécie não é anemófila, não é apomítica e não possui partenocarpia. A razão pólen/óvulo entre uma flor masculina e uma flor feminina foi alta (99.267: 1), classificando a espécie como xenogâmica.
\end{abstract}

Termos para indexação: Anacardiaceae, dioicia, polinização, restinga.

\section{CHARACTERIZATION OF THE FUNCTIONAL REPRODUCTIVE SYSTEM OF THE PINK-PEPPER (Schinus terebinthifolius Raddi), IN FLORIANÓPOLIS, SC, BRAZIL}

\begin{abstract}
Dioecy, as the reproductive system of S. terebinthifolius (Anacardiaceae), was investigated in an area with human interference and in a sandbank area, in the municipal district of Florianópolis, SC. During two reproductive periods the following pollination tests were performed: open pollination and manual cross-pollination have been developed in plants of both sexes, and tests of anemophily, agamospermy and parthenogenesis, accomplished only in female plants. Pollen grains have been germinated in different sucrose concentrations to verify their viability. The pollination treatments that resulted into fruit set were the open pollination, with the greatest average of $45 \%$, and manual cross-pollination, with the greatest average of $56,2 \%$. The other pollination tests did not result in fruit set, showing that the reduced gynoecium of the male flowers is not functional, proving dioecy of the species, neither the species is anemophilic, nor apomitic, and it does not present partenocarpy. The pollen/ovule ratio between a male and a female flower was high $(99,267: 1)$, classifying the species as xenogamic.
\end{abstract}

Index terms: Anacardiaceae, dioecy, pollination, sand-bank.

\section{INTRODUÇÃo}

Schinus terebinthifolius Raddi é uma Anacardiaceae pioneira, nativa do Brasil. É popularmente conhecida como aroeira-vermelha, aroeira-pimenteira e pimenta brasileira. Esta variação nos nomes se dá, principalmente, pelo fato de seus frutos possuírem a aparência de uma pequena pimenta de coloração rosa-avermelhada, por isso, também chamados de pimenta-rosa, "pink-pepper", "poivre rose", entre outros nomes.

A aroeira-vermelha possui inúmeras potencialidades medicinais e fitoquímicas. Alguns de seus metabólicos secundários têm auxiliado no tratamento e cura de diversos males (Guerra et al., 2000; Amorim \& Santos, 2003). Porém, atualmente, a espécie vem se destacando cada vez mais pelo consumo de seus frutos (pimenta-rosa), cuja demanda tem aumentado muito, tanto no mercado nacional como no internacional, que os utiliza como condimento alimentar.

$\mathrm{Na}$ atualidade, a exploração de seus frutos se restringe à coleta manual em populações naturais, presentes principalmente em áreas de restinga do litoral brasileiro. Apesar desta demanda, estudos relacionados à sua biologia reprodutiva não foram realizados e são escassos os estudos desta natureza em outras anacardiáceas nativas.

Embora seja uma espécie aparentemente pouco cultivada no Brasil, a pimenta-rosa possui um grande potencial para exploração e uso. Em viveiros, esta espécie floresce e frutifica já no primeiro ano de vida (Carvalho, 1994), o que sugere um retorno a curto prazo para quem investir em seu cultivo. Adicionalmente, sua alta plasticidade ecológica permite-lhe ocupar diversos tipos de ambientes e formações vegetais (Fleig \& Klein, 1989), favorecendo e aumentando as chances de seu cultivo em diversas regiões do Brasil.

Por suas flores serem aparentemente díclinas, sob o prisma morfológico, em função da redução ou aborto do gineceu e redução ou aborto do androceu, é necessário que se comprove, experimentalmente, a funcionalidade destes órgãos reduzidos, sendo que este padrão de apresentação floral parece ser comum em algumas outras anacardiáceas (Copeland, 1959; Oliveira \& Grotta, 1965; Fleig, 1987; Fleig \& Klein, 1989).

Assim, este trabalho teve a proposta de verificar e confirmar experimentalmente o sistema reprodutivo da aroeira-vermelha, por meio de tratamentos de polinização, em área de vegetação natural de restinga e em área antropomorfizada. Tem-se, com isso, o intuito de contribuir para a domesticação da espécie, para o manejo e produção de frutos, permitindo traçar novas estratégias que auxiliem na conservação das populações naturais e na manutenção das mesmas em diferentes ambientes.

\section{MATERIAL E MÉTODOS}

Os estudos foram conduzidos no município de Florianópolis, localizado na Ilha de Santa Catarina, durante os meses de outubro de 2002 a janeiro de 2003 (primeiro período reprodutivo), e entre fevereiro e julho de 2003 (segundo período reprodutivo), em duas áreas distintas. A Área de estudo (A), pertencente ao Centro de Treinamento da EPAGRI (CETRE), está localizada no bairro do Itacorubi $\left(27^{\circ} 34^{\prime} 55,2\right.$ ' $S$ e 48 30'17.4"W). Esta área é alterada antropomorficamente, onde se cultivam espécies anuais e pastagem. A área de estudo (B), situada na faixa litorânea, na costa leste da ilha, está sob constante influência marinha. Esta segunda área é quase que predominantemente coberta

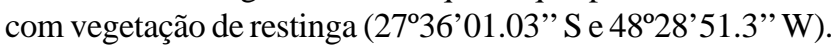

A estratégia reprodutiva desta espécie foi determinada, utilizando-se de 80 flores por tratamento de polinização, sendo que se utilizaram 20 flores em cada uma de quatro plantas (repetições), para cada um dos tratamentos de polinização, em ambas as áreas e nos dois períodos reprodutivos. Os tratamentos de polinização foram desenvolvidos entre outubro e novembro de 2002 (primeiro período reprodutivo), e de fevereiro a março de 2003 (segundo período reprodutivo).

\footnotetext{
(Trabalho 174/2003). Recebido: 21/11/2003. Aceito para publicação: 02/08/2004.

${ }^{2}$ Biólogo, M.Sc. Programa de Pós-Graduação em Recursos Genéticos Vegetais/UFSC. (mlenzi_pgrgv@ yahoo.com.br)

${ }^{3}$ Prof ${ }^{\circ}$ Ph.D. da Universidade Federal de Santa Catarina - UFSC, do Departamento de Fitotecnia, do Centro de Ciências Agrárias - CCA. Caixa Postal 476, CEP 88040900 Florianópolis, SC. 0xx (48) 331-5425. (aorth@ mbox1.ufsc.br)
} 
O tratamento de polinização livre foi realizado em todas as plantas sorteadas. Este foi considerado o tratamento-controle, pois nele foi permitida a polinização aberta (sem ensacamento) realizada pelos possíveis agentes de transferência de pólen de cada local e ano.

$\mathrm{O}$ tratamento de polinização cruzada manual foi aplicado em flores ensacadas, no dia que antecedeu a antese, com sacos de papel manteiga para impedir a polinização natural. Uma mistura de pólen proveniente de flores masculinas foi armazenada em eppendorf, e posteriormente transferida para os estigmas das flores femininas com o auxílio de um pincel macio. Posteriormente, as flores novamente foram ensacadas por todo o período de antese.

O tratamento de polinização cruzada manual em flores masculinas foi utilizado para se determinar viabilidade do gineceu reduzido encontrado nas flores masculinas. A metodologia utilizada para este tratamento foi igual à do tratamento de polinização manual.

O tratamento de anemofilia foi realizado em plantas femininas distintas das demais. Neste tratamento, as flores foram ensacadas com sacos de tecido de voile com mesh de 500 micras, no dia anterior ao da antese, para se evitar a presença de insetos e outros animais transportadores de pólen e permitir a eventual passagem de grãos de pólen transportados pelos ventos.

Para o tratamento de agamospermia, foi procedida a retirada das anteras (emasculação) nas flores masculinas, e nas femininas, a retirada das anteras atrofiadas. Estas flores foram ensacadas com sacos de papel manteiga, no dia que antecedeu a abertura floral, para impedir a polinização natural, desensacadas na antese para que se pudesse realizar a emasculação e, em seguida, novamente ensacadas.

Todas as plantas, inflorescências e flores sorteadas foram marcadas com fitas e linhas coloridas, específicas para cada teste de polinização. Para o teste de polinização livre, foi utilizada linha de costura, com coloração em tons de caramelo, pois esta cor, aparentemente, não assustou os insetos visitantes florais e, tampouco, impediu as suas visitações às flores da aroeira-vermelha.

O tratamento de partenocarpia foi determinado através da utilização de 80 frutos, oriundos de flores polinizadas naturalmente. Os frutos em laboratório foram observados sob microscópio esteroscópio 4X de aumento, observou-se a ausência de embrião (paternocarpia) ou a presença de um embrião, levando-se em consideração se as sementes possuíam alguma indicação de predação ou parasitismo, sendo estas descartadas.

Os dados resultantes dos tratamentos de polinização foram submetidos à Análise de Variância (ANOVA), a 95\% de confiabilidade (Sokal \& Rohlf, 1981).

A partir dos resultados positivos obtidos nos tratamentos de polinização, determinaram-se as taxas médias de frutificação efetiva.

Para se obter a taxa média de frutificação efetiva natural, escolheram-se aleatoriamente 32 cachos de frutos (drupas) de plantas femininas de aroeiras-vermelhas na área de restinga, e destas se calculou a média do número de frutos. Deste modo, foi possível comparar a taxa de frutificação do tratamento de polinização livre com a taxa de frutificação efetiva natural, levando-se em consideração apenas os dados da área preservada, a fim de perceber como a espécie se comporta reprodutivamente em seu ambiente natural.

A quantificação do número de grãos de pólen foi determinada seguindo-se a metodologia proposta por Kearns \& Inouye (1993), e o número de óvulos foi determinado em 120 frutos, sob microscópio estereoscópio (16X). A razão pólen/óvulo (P/O) foi determinada seguindose a fórmula proposta por Cruden (1977), onde a razão pólen/óvulo (P/O) é obtida através da divisão da média do número de grãos de pólen em uma flor masculina pelo número médio de óvulos em uma flor feminina.

Através de visitas sistemáticas às áreas de estudo e às plantas marcadas, observaram-se naturalisticamente os grupos de visitantes florais presentes sobre as flores masculinas e femininas da aroeiravermelha.

\section{RESULTADOS E DISCUSSÃO}

A análise dos resultados dos diferentes tratamentos de polinização evidencia que nem todos responderam com a frutificação. Os resultados negativos para os tratamentos de polinização cruzada manual em flores masculinas demonstraram que o gineceu reduzido destas flores não é funcional, pois em nenhuma das áreas e épocas de floração foi constatada a formação de frutos nas inflorescências com flores classificadas morfologicamente como masculinas. A falta de frutificação no teste de anemofilia indicou que a espécie não é anemófila, ou seja, os grãos de pólen da aroeira não são transportados pelo vento. Observou-se também que nenhuma flor frutificou sem a presença de grãos de pólen (fertilização), e isto demonstrou que a aroeira-vermelha não é uma espécie apomítica, isto é, não possui a agamospermia como uma estratégia reprodutiva. Todas as sementes observadas e consideradas intactas (sem indícios de predação ou parasitismo) possuíam um embrião, indicando, portanto, que a espécie não é partenocárpica. Apenas os tratamentos de polinização livre e polinização cruzada manual em flores femininas resultaram em frutificação.

Os resultados positivos para os tratamentos de polinização livre e cruzada manual em flores femininas demonstraram que esta espécie é dióica, e que suas flores são díclinas. Sua estratégia de polinização é a cruzada (xenogamia/alogamia), desta forma necessitando de agentes bióticos para o transporte dos seus grãos de pólen. Pelas observações em campo, constatou-se que esta transferência de pólen está sendo mediada exclusivamente por insetos polinizadores, e isto foi confirmado durante as visitas às áreas de estudo, onde se observou um grande e diversificado número de visitantes florais nas flores da aroeira-vermelha, durante todo o período de floração. Estes insetos constituíram-se, na sua maioria, de abelhas (Apidae, Halictidae, Colletidae e Megachilidae), de moscas (Syrphidae, Calliphoridae, Muscidae, entre outras) e de vespas (Vespidae, Pompilidae e Sphecidae), que visitaram as flores de ambos os sexos ao longo de todo o dia. Desta forma, a aroeira-vermelha pode ser classificada como uma espécie possuidora da síndrome de entomofilia e ser generalista quanto à diversidade desta entomofauna visitante floral, tomando-se como base a classificação proposta por Faegri \& Van Der Pijl(1979).

A significância $(\mathrm{QM}=43,71)$ constatada através da análise de variância (Tabela 1), para o sistema reprodutivo, ocorreu entre os tratamentos de polinização $(\mathrm{C})$. Os demais resultados não foram significativos (Tabela 1). A ausência de interações entre anos, áreas e tratamentos demonstra que as plantas estudadas se comportam reprodutivamente de maneira semelhante na sua estratégia de polinização, como também em locais aparentemente distintos, e isso pode ser explicado pelo fato de a aroeira-vermelha ser uma planta pioneira, com grande plasticidade ecológica e, portanto, adaptada a diferentes ambientes.

Analisando-se os resultados na Tabela 2, verifica-se que a significância constatada na análise de variância (Tabela 1), entre os

TABELA 1 - Resumo da Análise de Variância dos resultados obtidos nos tratamentos.

\begin{tabular}{|c|c|c|}
\hline Causas da Variação & G. L. & Q. M. \\
\hline $\mathrm{A}=$ ano & 1 & $1,38^{\mathrm{NS}}$ \\
\hline $\mathrm{B}=$ área & 1 & $5,51^{\mathrm{NS}}$ \\
\hline $\mathrm{C}=$ Tratamento & 1 & $43,71 * *$ \\
\hline \multicolumn{3}{|l|}{ INTERAÇÃO } \\
\hline $\mathrm{AB}$ & 1 & $0,80^{\mathrm{NS}}$ \\
\hline $\mathrm{AC}$ & 1 & $7,41^{\mathrm{NS}}$ \\
\hline $\mathrm{BC}$ & 1 & $5,46^{\mathrm{NS}}$ \\
\hline $\mathrm{ABC}$ & 1 & $3,71^{\mathrm{NS}}$ \\
\hline RESÍDUO & 24 & 3,52 \\
\hline TOTAL & 31 & \\
\hline
\end{tabular}

$\mathbf{N S}=$ não significativo e, ${ }^{* *}=$ significativo pelo " $F$ " teste, $\alpha=0,05$ de significância. *Dados transformados em: $\operatorname{arc}-\operatorname{sen}(\mathrm{x}+1)^{1 / 2}$. 
tratamentos de polinização $(\mathrm{C})$, está associada às médias dos tratamentos de polinização livre e polinização cruzada manual, que diferiram significativamente entre si $(\mathrm{F}=12,38 ; \mathrm{p}<0,05)$. Essa diferença nas médias demonstra que há uma tendência de a polinização cruzada manual resultar em maior frutificação, pois as maiores taxas de frutificação $(56,25 \%$ e $51,25 \%$ ) foram encontradas no ano de 2002, na área antropomorfizada e na área natural, respectivamente, nesse tratamento (Tabela 2). Contudo, os resultados dos tratamentos de polinização livre apresentaram taxas de frutificação relativamente altas $(43,75 \%$ e $41,25 \%)$, ambas no ano de 2003, na área antropomorfizada e na área natural, respectivamente (Tabela 2), devido à presença de maior número de polinizadores nesta época.

Estes resultados demonstram que a aroeira-vermelha responde bem à manipulação artificial (humana) de suas flores, mas que, também, está obtendo um excelente sucesso reprodutivo através da polinização livre (xenogamia/alogamia). Stephenson (1981) e Vieira et al. (1992) sugerem que polinizadores podem ser um dos fatores limitantes à produção natural de frutos. Porém, aparentemente, a aroeira-vermelha resolveu este problema, apresentando flores generalistas, que aumentam assim, sobremaneira, suas chances de fertilização através de maior e diversificada entomofauna, o que pode ser constatado pelas taxas de frutificação do tratamento de polinização livre (Tabela 2).

TABELA 2 - Número, taxa de frutificação (\%) e média do número de frutos formados nos tratamentos de polinização livre e cruzada manual, nas duas áreas de estudo $(\mathrm{N}=80$ flores por tratamento) de Schinus terebinthifolius Raddi, durante os anos de 2002 e 2003, Florianópolis-SC.

\begin{tabular}{|c|c|c|c|c|}
\hline Tratamentos de & Ano & \multicolumn{2}{|c|}{ Áreas de estudo } & Média* \\
\hline & & A & B & \\
\hline & 2002 & 10 & 28 & \\
\hline $\begin{array}{l}\text { Polinização } \\
\text { livre }\end{array}$ & 2003 & $\begin{array}{c}(12,5 \%) \\
35 \\
(43,75 \%)\end{array}$ & $\begin{array}{c}(35 \%) \\
33 \\
(41,25 \%)\end{array}$ & $\begin{array}{c}26,5 \\
(33,12 \%) a\end{array}$ \\
\hline Polinização & 2002 & $\begin{array}{c}45 \\
(56,25 \%)\end{array}$ & $\begin{array}{c}41 \\
(51,25 \%)\end{array}$ & 39 \\
\hline cruzada manual & 2003 & $\begin{array}{c}39 \\
(48,75 \%)\end{array}$ & $\begin{array}{c}30 \\
(37,5 \%)\end{array}$ & $(48,43 \%) b$ \\
\hline
\end{tabular}

*Médias seguidas por letras iguais, nas mesmas colunas, não diferem entre si, pelo " $F$ " teste, $\alpha=0,05$ de significância.

Adicionalmente, tem-se observado uma redução significativa de grupos de insetos polinizadores de plantas (Laroca \& Orth, 2002), fato este que deve ser levado em consideração quando se avalia a frutificação natural observada em diferentes ambientes e em diferentes épocas, mormente em ambientes alterados pela ação do homem. Neste contexto, percebe-se a existência de uma taxa média de frutificação efetiva $(12,5 \%)$ inferior às demais, no primeiro período reprodutivo, na área alterada (Tabela 2). Este resultado pode ser explicado pela ausência de insetos visitantes (potenciais polinizadores), os quais praticamente não foram observados durante as visitas ao local, neste período, e isto confirma mais uma vez, que a espécie necessita dos insetos (como vetores de pólen) para se reproduzirem e realizarem as trocas gênicas entre e dentro das populações de S. terebinthifolius. Corroborando essa afirmação, no segundo ciclo e nessa área alterada, foi constatada taxa média de polinização livre maior (35\%), resultante de maior presença de visitantes florais, em especial das abelhas exóticas Apis mellifera.

Apesar de esse estudo não ter contemplado uma análise de custos do método de polinização cruzada manual, pode-se perceber, durante os trabalhos de polinização em campo, que essa forma de polinização não é a mais indicada, nesse particular. O pequeno tamanho das flores $(<5 \mathrm{~mm})$ e o grande número dessas seriam os fatores limitantes para o uso dessa metodologia em áreas de cultivo mais intensificado, pois demandaria muito tempo e mão-de-obra qualificada e em grande quantidade. Portanto, a polinização livre (mediada por abelhas $A$. mellifera) seria o método mais indicado para o aumento da frutificação da aroeira-vermelha em áreas de cultivo.

Outra observação relevante quanto à manipulação das inflorescências e flores da aroeira-vermelha é a queda de um grande número destas. Uma explicação plausível para este fato seria o aumento na produção de etileno, aumento este que pode ter sido causado pelas altas temperaturas no período (verão/outono), ou então, por traumas causados durante a manipulação das inflorescências e botões florais (Ferri, 1986; Arteca, 1996). Além disso, o posterior ensacamento com saquinhos de papel amanteigado possivelmente favorece a concentração do etileno em seu interior. Este problema foi atenuado, procurando-se diminuir consideravelmente os traumas quando na manipulação das inflorescências, botões florais e no seu posterior ensacamento, e desenvolvendo-se os tratamentos de polinização preferencialmente nas horas com as temperaturas mais amenas do dia.

A média de flores femininas, verificada em uma inflorescência, foi de 346,25 $\pm 53,91(\mathrm{~N}=8)$, e a média de frutos em um cacho foi de 120,18 $\pm 26,89$ ( $N=32$ ). Portanto, a taxa de frutificação efetiva natural determinada para a aroeira-vermelha, nesse estudo, foi da ordem de $34,7 \%$, sendo esta muito próxima da taxa média de frutificação obtida nos tratamentos de polinização livre na área natural (34\%). Este resultado demonstra que a metodologia utilizada neste estudo para o teste de polinização livre foi adequada.

Fuzeto et al. (2001) obtiveram uma taxa de frutificação efetiva da ordem de $32 \%$ para a espécie dióica Cabralea canjerana, originada de polinização aberta, a qual corresponde, mormente, ao teste de polinização livre neste estudo. Stephenson (1981) revisou a taxa de frutificação efetiva em 59 espécies vegetais, mostrando que apenas algumas destas possuíam uma frutificação efetiva superior a $40 \%$. Duas outras espécies de anacardiáceas, segundo este mesmo autor, apresentaram taxas de frutificação inferiores à encontrada para $S$. terebinthifolius neste trabalho: Anacardium occidentale L. apresentou uma taxa de frutificação de $10 \%$ e Mangifera indica L. apresentou uma taxa de frutificação que variou de 0,1 a $0,4 \%$.

A flor masculina possui, em média, 99.267 grãos de pólen, e a feminina é uniovulada. A razão pólen/óvulo para a espécie é de 992.667:1, considerando-se a produção de pólen de uma flor masculina para o óvulo de uma flor feminina. Seguindo-se a classificação proposta por Cruden (1977), determinou-se que $S$. terebinthifolius é uma espécie que apresenta uma razão pólen/óvulo alta, portanto considerada uma espécie xenogâmica, ou seja, dependente da polinização cruzada para obter seu sucesso reprodutivo, uma conclusão bastante óbvia para uma espécie dióica como S. terebinthifolius.

A razão pólen/óvulo está diretamente relacionada ao modo de polinização e ao sistema reprodutivo das espécies e, tratando-se de uma espécie xenogâmica, maior oferta de grãos de pólen gera um substancial benefício ao seu sistema reprodutivo, pois maior carga de grãos de pólen é depositada sobre os estigmas, e maior número de flores podem receber este pólen (Bertin, 1989). Espécies com um grande número de óvulos requerem maior quantidade de grãos de pólen sobre seus estigmas, comparadas às espécies com poucos óvulos por flor (Ramírez, 1995), e a carga de pólen requerida para produzir frutos em espécies uniovuladas como a aroeira-vermelha, é menor (Armstrong \& Irvine, 1989). Esta hipótese explica em parte o sucesso da fertilização de um grande número de flores femininas nas plantas de aroeira-vermelha e suas altas taxas de frutificação observadas nos tratamentos de polinização livre (Tabela 2), isso se ocorrer a presença de agentes polinizadores.

O início do processo do amadurecimento, e conseqüente dispersão dos frutos, ocorreu após 30 dias da floração, perdurando até o mês de janeiro de 2003 (primeiro período reprodutivo) e julho de 2003 (segundo período reprodutivo). Quando degustados, os frutos oriundos das aroeiras-vermelhas da área de restinga apresentaram um sabor salgado e considerados de qualidade inferior para consumo, provavelmente devido à presença dos ventos maritmos com altos teores de $\mathrm{NaCl}$ (sal). Já os frutos colhidos na área alterada, mais distante da influência marinha, possuíam um sabor doce-apimentado, típico da 
pimenta-rosa, sendo, portanto, os mais aconselhados para consumo. Estas observações preliminares do sabor são relevantes, contudo novos estudos que contemplem metodologias mais especificas, fazem-se necessários, para se avaliar o sabor e se verificar as qualidades nutricionais da pimenta-rosa em diferentes ambientes.

\section{CONCLUSÃO}

1. As flores de S. terebinthifolius, além de possuírem órgãos reprodutivos normais, possuem órgãos reduzidos que não são funcionais, o que comprova a dioicia da espécie.

2. As aroeiras-vermelhas das áreas estudadas responderam com alto sucesso reprodutivo aos tratamentos de polinização cruzada manual e livre, exceto no primeiro período reprodutivo na área alterada, devido à baixa presença de visitantes florais. Portanto, entende-se que a redução da visitação ou da presença de polinizadores às flores da aroeira-vermelha é um fator limitante para o sucesso reprodutivo da espécie, pois, com menor número de polinizadores, a frutificação tende a cair.

3. O método de polinização livre (mediado por insetos) é o mais indicado para o aumento da frutificação da aroeira-vermelha, devido ao pequeno tamanho de suas flores.

4. A relação pólen/óvulo é elevada e caracteriza a planta como xenogâmica, ou seja, dependente obrigatoriamente da ação de agentes polinizadores, nesse caso, de diversos grupos de insetos, em especial das abelhas.

5. Nesse sentido, os resultados obtidos nesse estudo tornamse um indicativo para a conservação dos remanescentes de restinga e daqueles próximos às áreas de cultivo, como garantia da sobrevivência de inúmeras espécies animais e vegetais e, por conseguinte, das próprias populações de aroeiras-vermelhas.

\section{REFERÊNCIAS BIBLIOGRÁFICAS}

AMORIM, M. M. R. de; SANTOS, L. C. Tratamento da vaginose bacteriana com gel vaginal de Aroeira (Schinus terebinthifolius Raddi): ensaio clínico randomizado. Revista Brasileira de Ginecologia e Obstetrícia, v. 25, n. 2, p. 95-102, 2003.

ARTECA, R. N. Plant growth substances: principles and applications. New York: Chapman e Hall, 1996. 332p.

ARMSTRONG, J. E.; IRVINE, A. K. Flowering, sex ratios, pollen-ovule ratios, fruit set, and reproductive effort of a dioecius tree, Myristica insipida Columbus, Myristicaceae, in two different rain forest communities. American Journal of Botanic, v. 76, p. 74-85, 1989.

BERTIN, I. R. Pollination biology. In: WARREN, G. A. Plant-animal interactions. New York: Mcgraw-hill Book Company, 1989. p. 23-83.

CARVALHO, P. E. R. Espécies florestais brasileiras: Recomendações silviculturais, potencialidades e uso da madeira. Brasília: EMBRAPA -SPI, 1994. 640p.
COPELAND, H. F. The reproductive structures of Schinus molle (Anacardiaceae). Madrono, Berkeley, v. 15, p. 14-24, 1959.

CRUDEN, R. W. Pollen-ovule ratio: a conservative indicator of breeding system in flowering plants. Evolution, Lawrence, v. 31, p. 32-36, 1977.

FAEGRI, K.; VAN DER PIJL, L. The principles of pollination ecology. 3. ed. New York: Pergamon Press, 1979. 291p.

FLEIG, M. Anacardiaceae. Flora Ilustrada do Rio Grande do Sul. Porto Alegre: Boletim do Instituto de Biociências, v. 18, n. 42, 1987. p. 1-72.

FLEIG, M.; KLEIN R. M. Anacardiáceas. Flora Ilustrada Catarinense. Itajaí-SC: $1989.64 p$.

FERRI, M. G. Fisiologia vegetal. São Paulo: EPU \& EDUSP, 1986. v. 2, 401p.

FUZETO, A. P.; BARBOSA, A. A. A.; LOMÔNACO, C. Cabraela canjerana subsp. polytricha (Adri. Juss.) Penn. (Meliaceae), uma espécie dióica. Acta Botânica Brasílica, São Paulo, v. 15, n. 2, p. 167-175, 2001

GUERRA, Mª. J. M.; BARREIRO, M. L.; RODRIGUEZ, Z. M.; RUBALCADA, Y. Actividad antimicrobiana de un extracto fluido al 80\% de Schinus terebinthifolius Raddi. Inst. Superior de Ciencias Médicas de La Habana. Revista Cubana Plant. Med., v. 5, n. 1, p. 523, 2000 .

KEARNS, C. A.; INOUYE, D. W. Techniques for pollination biologists. Niwot: University Press of Colorado, 1993. 583p.

LAROCA, S; ORTH, A. I. Melissocoenology: historical perspective, method of sampling, and recommendations to the "Program of conservation and sustainable use of pollinator, with emphasis on bess" (ONU). IN: KEVAN P.; IMPERATRIZ-FONSECA. V. L. (Ed.) Pollinating bess: the conservation link between agriculture and nature - Brasilia: Ministry of Environment, 2002. p. 217-225.

OLIVEIRA, F.; GROTTA, A. S. Contribuição ao estudo morfológico e anatômico de Schinus terebinthifolius Raddi Anacardiaceae. Revista de Farmácia Bioquímica, São Paulo, v. 3, n. 2, p. 271-293, jul./dez. 1965.

RAMÍREZ, N. Producción y costo de frutos y semillas entre modos de polinización en 232 especies de plantas tropicales. Revista de Biologia Tropical, v. 43, n. 1-3, p. 151-159, 1995.

SOKAL, R. R; ROHLF, F. J. Biometry. 2. ed. New York: W.H. Freeman and C., 1981.859p.

STEPHENSON, A. G. Flower and fruit abortion: proximate causes and ultimate functions. Annual Review of Ecology and Systematics, Palo Alto, v. 12, p. 253-279, 1981.

VIEIRA, M. F.; MEIRA, R. M . S. A.; QUEIROZ, L. P.; MEIRA-NETO, J. A. A. Polinização e reprodução de Jacaranda caroba (Vell.) DC. (Bignoniaceae) em área de Cerrado do Sudeste Brasileiro. In: SBSP, 8., 1992, Anais... p. 13-19. 